\title{
STUDI PERKUATAN KOLOM EKSISTING DENGAN PEN-BINDER UNTUK PENINGKATAN DAKTILITAS KOLOM BETON BERTULANG
}

\author{
Anang Kristianto, Ichsan Yansusan \\ Jurusan Teknik Sipil, Universitas Kristen Maranatha \\ Jalan Prof. drg. Soeria Sumantri, MPH, No. 65, Bandung, 40164 \\ e-mail: anang.kristianto@gmail.com
}

\begin{abstract}
ABSTRAK
Salah satu persyaratan penting yang diperlukan dalam desain bangunan tahan gempa yang berhubungan dengan detailing tulangan adalah penggunaan tulangan pengekang pada kolom sistem rangka pemikul momen. Pemasangan tulangan pengekang pada perkuatan kolom eksisting pada umumnya mengalami kesulitan untuk mememenuhi standar SNI, hal ini terjadi karena kondisi di lapangan yang tidak memungkin membuat tulangan pengekang dengan kait $135^{\circ}$. Penelitian yang dipaparkan dalam makalah ini memperkenalkan suatu alat sederhana yang disebut "pen-binder" yang dapat dipasangkan pada tulangan pengekang tidak standar di lapangan untuk perkuatan kolom. Spesimen yang digunakan dalam pengujian ini terdiri dari 9 buah kolom dengan luas penampang $170 \mathrm{~mm} \times 170 \mathrm{~mm}$ dan tinggi $480 \mathrm{~mm}$ yang terdiri dari tiga tipe. Benda uji kolom dengan sudut kait $135^{\circ}$ (K135), benda uji kolom dengan sudut kait $90^{\circ}$ (K90) dan benda uji kolom yang memiliki pengekang dengan sudut kait $90^{\circ}$ yang diberi perkuatan pen-binder (KPB) setelah berumur 28 hari. Untuk memberikan hasil yang akurat maka untuk setiap tipe benda uji dibuat 3 buah benda uji kolom. Spesimen kolom diuji tekan menggunakan Universal Testing Machine berkapasitas $1000 \mathrm{kN}$. LVDT (Linear Variable Differential Transducer) ditempatkan pada muka kolom untuk mengukur deformasi aksial dari benda uji kolom. Regangan pada tulangan pengekang diukur dengan menggunakan strain gauge yang ditempatkan pada tulangan longitudinal dan transversal. Spesimen dibebani hingga mencapai kapasitas beban maksimumnya. Daktilitas aksial yang terjadi pada kolom tidak standar, kolom standar dan kolom dengan perkuatan pen-binder berturut-turut adalah 1,3, 7,5 dan 17,5. Penggunaan pen-binder untuk tulangan pengekang yang tidak standar meningkatkan daktilitas sebesar $133 \%$ lebih tinggi dari pada tulangan pengekang standar.
\end{abstract}

Kata kunci: tulangan pengekang, kolom, beton bertulang, pen-binder, daktilitas.

\section{ABSTRACT}

One of the important requirements for earthquake resistant buildings associated with reinforcement detailing is the use of confinement reinforcement in moment resisting frame. Installation of confinement reinforcement for strengthening on existing columns are difficult to meet SNI code requirement, because of the conditions on the site are difficult to make confinement reinforcement with $135^{\circ}$ hooks. The research study reported in this paper introduces a simple device called "pen-binder" that can be attached onto the non-compliance confining reinforcement at construction sites for strengthening columns. The specimens tested in this study were 9 column specimens, with $170 \mathrm{~mm} \times 170 \mathrm{~mm}$ in cross section and $480 \mathrm{~mm}$ in height which consists of three types. Column specimens with the hook angle $135^{\circ}$ (K135), column specimens with hook angle $90^{\circ}$ (K90) and column specimen with hook $90^{\circ}$ which was strengthening with pen-binder (KPB) after 28 days. To give an accurate result for each type of column specimens are made three specimens. The column specimens were tested using a universal compression testing machine with a $1000 \mathrm{kN}$ load capacity. LVDTs (Linear Variable Differential Transducers) was placed on column face to measure axial deformations of the specimens. Strain in confining reinforcement was measured using electric strain gauges were placed on longitudinal and transverse reinforcement. The specimens were loaded until reach maximum column capacity. The test results shows the use of pen-binder improve ductility very significant. Columns specimen with pen-binder (KPB) is much better than columns specimens with non-compliance confinement reinforcement (K90) and

Studi Perkuatan Kolong Eksisting Dengan Pen-Binder Untuk Peningkatan Daktilitas

Kolom Beton Bertulang (Anang Kristianto, Ichsan Yansusan) 
standard confinement reinforcement (K135). Axial ductility in the columns specimens with noncompliance confinement, standard column and the column with pen-binder are respectively 1.3, 7.5 and 17.5. Using pen-binder reinforcement for non-compliance confinement reinforcement increase ductility as much as 133\% higher than standard confinement (K135).

Keywords : confinement, column, reinforced concrete, pen-binder, ductility.

\section{PENDAHULUAN}

Standar Nasional Indonesia (SNI) 03-2847-2012 mensyaratkan diberikannya tulangan pengekang kait standar dengan sudut $135^{\circ}$ serta panjang kait yang masuk ke dalam inti beton terkekang sebesar 6 diameter atau $75 \mathrm{~mm}$ pada elemen kolom yang dibangun di daerah rawan gempa.Ketidaktepatan ataupun kesalahan dalam pemasangan tulangan pengekang ini dapat mengakibatkan kegagalan bangunan pada saat mengalami beban gempa. Pada umumnya mengingat kurangnya pengawasan di lapangan terhadap pelaksanaan proyek banyak pelaksana konstruksi pada akhirnya memasang dengan menggunakan tulangan pengekang dengan kait $90^{\circ}$ hal ini banyak diamati dari kegagalan bangunan yang terjadi di daerah rawan gempa akibat beberapa kejadian gempa terakhir.

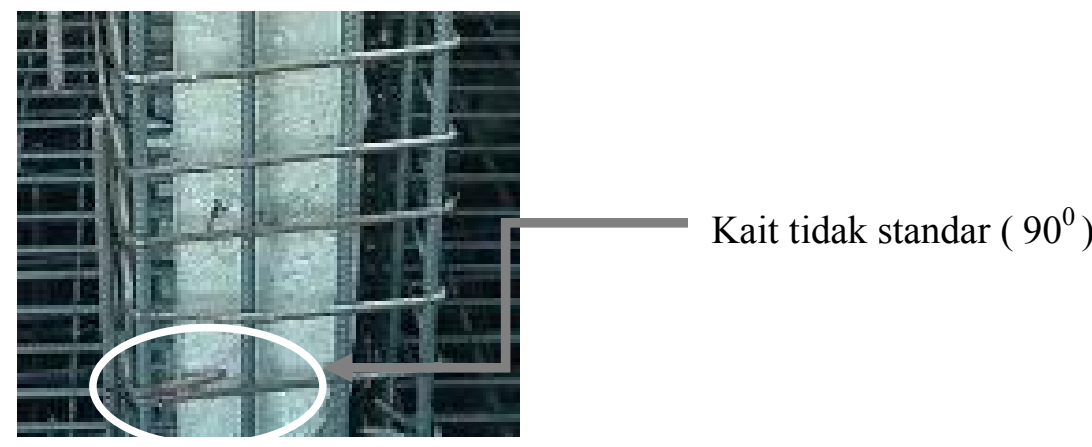

\section{Gambar 1.Perkuatan kolom eksisting dengan metode concrete jacketing}

Hal lain yang penting adalah terkait pemasangan tulangan pengekang yang memenuhi standar untuk keperluan perbaikan atau perkuatan struktur kolom dengan menambahkan tulangan baru dan dilakukan pengecoran tambahan beton (concrete jacketing) yang pada umumnya tidak mudah diimplementasikan dilapangan. Pada saat pekerjaan perkuatan dilaksanakan dilapangan, kondisi kolom sudah menyatu dengan elemen struktur lain sehingga cukup sulit untuk memasang tulangan pengekang dengan sudut $135^{\circ}$,sehingga pada umumnya tulangan tambahan dipasang dengan sudut $90^{\circ}$ (Gambar 1). Seringkali juga akibat kesulitan pemasangan ini dilakukan modifikasi pemasangan tulangan pengekang oleh pelaksana konstruksidimana kinerjanya belum teruji melalui pengujian di laboratorium. Hal ini memotivasi perlunya suatu penelitian 
untuk mengembangkan perkuatan struktur kolom eksistingyang mudah pemasangannya di lapangan serta masih memenuhi persyaratan SNI sebagai kolom yang dibangun pada daerah rawan gempa.

Salah satu inovasi yang sedang dikembangkan saat ini adalah perkuatan dengan menggunakan pen-binder (Kristianto, A. et al, 2012). Pen-binder adalah suatu kait yang dipasang pada tulangan pengekang sedemikian rupa sehingga membantu tulangan pengekang tetap pada posisinya pada saat beban aksial bekerja. Pada penelitian terdahulu pen-binder dipasang dalam kondisi beton belum dicor, untuk penelitian ini dilakukan pemasangan pen-binder pada kondisi beton sudah dicor untuk merepresentasikan perkuatan pada kondisi eksisting.

\section{TINJAUAN LITERATUR}

Kolom (pada umumnya berarah vertikal) merupakan salah satu elemen struktur dari sistem rangka yang memikul beban dari balok serta elemen struktur lain diatasnya. Pada umumnya dominan gaya yang bekerja pada elemen kolomadalah gaya aksial tekan. Keruntuhan suatu kolom merupakan kondisi kritis yang dapat menyebabkan keruntuhanlantai yang bersangkutan dan bahkan juga seluruh struktur. Kondisi inilah yang menyebabakan keruntuhan kolom struktural merupakan hal yang sangat dihindari sehingga dalam perencanaannya harus lebih diperhatikan dengan memberikan kekuatan cadangan yang lebih tinggi dari pada balok ataupun elemen struktur horizontal lainnya, dalam desain struktur tahan gempa hal ini dikenal dengan istilah kolom kuat balok lemah (strong column weak beam). Untuk mendapatkan kondisi kolom kuat balok lemah maka harus dibuat perencanaan sedemikian rupa sehingga pada saat beban gempa terjadi maka balok direncanakan untuk mendisipasi energi gempa melalui pembentukan sendi plastis (pada kedua ujungnya) sementara itu kolom harus sanggup bertahan selama terjadi disipasi energi pada balok. Perkuatan pada kolom sangat diperlukan apabila dalam perkembangannya terjadi kerusakan pada kolom atau perubahan beban rencana yang memerlukan desain ulang untuk perkuatan.

\subsection{Perkuatan Kolom}

Perkuatan adalah suatu tindakan modifikasi struktur, dengan tujuan untuk menaikkan kekuatan, kekakuan serta daktilitas struktur. Penelitian tentang analisisperkuatan struktur diawali pada tahun 1960 oleh negara-negara maju sampai sekarang. Penelitian mengenai perkuatan dilatar belakangi oleh beberapa hal yaitu kesalahan dalam implementasinya di lapangan, kerusakan elemen struktur yang terjadi 
akibat bencana (gempa bumi) serta perubahan fungsi struktur yang mengakibatkan perbedaan antarabeban rencana dengan beban disain.

Retrofitting merupakan salah satu upaya dalam meningkatkan kekuatan dan daktilitas sebuah struktur yang telah rusak. Ada dua jenis Retrofitting yang dapat dilakukan yaitu :

- Repairing adalah upaya dalam mengembalikan kekuatan dan daktilitas struktur yang telah rusak kembali seperti kondisi awal.

- Strengthening adalah upaya memberikan penambahan kekuatan atau perkuatan dari struktur yang telah ada dengan menambahkan material baru.

Setelah diketahui dan dimungkinkan struktur dapat diperkuat maka langkah selanjutnya adalah pemilihan metode perkuatan untuk masing-masing elemen struktur. Pemilihan metode perkuatan dipengaruhi oleh beberapa pertimbangan, antara lain : pertimbangan efektivitas perkuatan, kemudahan dalam pelaksanaan atau pemasangannya, serta biaya yang diperlukan.Beberapa metoda perkuatan yang telah banyak diimplementasikan dalam beberapa tahun terakhir antara lain adalah:memberi penyelubungan beton pada struktur (Concrete Jacketing), penyelubungan baja pada struktur (Steel Jacketing), memberi lapisan lembaran material komposit yang terbuat dari CFRP (Carbon Fiber Reinforced Polimer), GFRP (Glasses Fiber Reinforced Polimer) atau AFRP (Aramid Fiber Reinforced Polimer).

\subsection{Perkuatan Kolom Dengan Menggunakan Material Pen-Binder}

Perilaku kolom beton bertulang yang daktail dan tahan goyangan beban gempa memerlukan suatu bentuk dan konfigurasi tulangan pengekang yang mampu menahan inti beton agar tidak lepas sehigga memberikan kekakuan yang cukup selama beban bekerja. Ide dasar penggunan pen-binder sebagai elemen pengikat adalah untuk membantu tulangan pengekang menahan inti beton tetap pada posisinya hingga menjamin proses plastifikasi berlangsung seperti yang dikehendaki dalam desain elemen struktur tersebut.Pemasangan tulangan pengekang dengan kait $90^{\circ}$ merupakan salah satu contoh tulangan pengekang yang memerlukan elemen pengikat agar pada saat beban aksial dan lateral bekerja tidak mengakibatkan kegagalan. Elemen pengikat atau pen-binder ini harus bekerja sedemikian rupa sehingga memiliki kemampuan untuk menahan titik-titik tertentu yang akan membuka akibat ekspansi lateral inti beton.

Gambar 2 memperlihatkan ilustrasi konsep pen-binder sebagai elemen pengikat tulangan pengekang yang dipasang pada daerah kait tidak standar. 


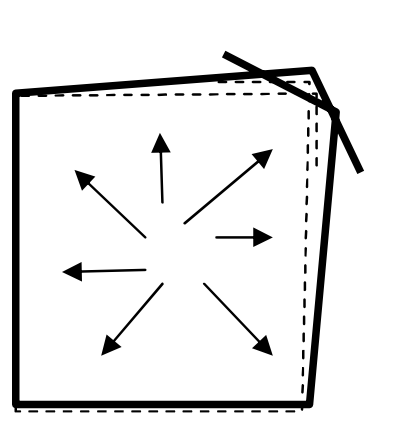

(a)

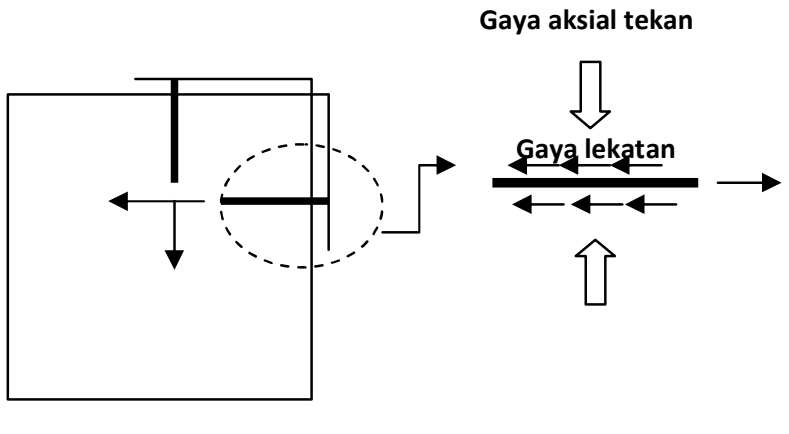

(b)

Gambar 2. Ilustrasi konsep pen-binder sebagai elemen pengikat: (a). Tulangan pengekang dengan kait tidak standar tanpa pen-binder. (b). Penambahan pen-binder pada tulangan pengekang.

Pemasangan pen-binder pada posisi tertentu seperti dalam ilustrasi Gambar 2 mengikat tulangan pengekang sehingga kait tidak terbuka seperti pada Gambar 2.a. Penbinder memanfaatkan gaya aksial yang mengekang inti beton dalam arah longitudinal dengan mengembangkan kapasitas lekatannya sehingga membantu menahan tulangan pengekang menahan ekspansi lateral beton. Untuk menjamin ikatan antara tulangan pengekang dengan pen-binder dapat berlangsung hingga deformasi aksial dan lateral yang tinggi maka pen-binder dibentuk menyerupai pengikat silang dimana bagian ujung pen-binder ditekuk mengelilingi tulangan pengekang dengan sudut $180^{\circ}$, sementara ujung lainnya tertanam pada daerah inti beton.

\section{PROGRAM PENGUJIAN BENDA UJI}

\subsection{Benda Uji}

Pada penelitian ini dibuat benda uji kolom dengan dimensi penampang $170 \mathrm{~mm} x$ $170 \mathrm{~mm}$, tinggi $480 \mathrm{~mm}$ yang terdiri dari 3 tipe yaitu :benda uji kolom dengan sudut kait $135^{\circ}$ (K135), benda uji kolom dengan sudut kait $90^{\circ}$ (K90) dan benda uji kolom yang memiliki pengekang dengan sudut kait $90^{\circ}$ kemudian diberi perkuatan pen-binder (KPB) setelah berumur 28 hari. Untuk memberikan hasil yang akurat maka untuk setiap tipe benda uji dibuat 3 buah benda uji kolom. Gambar 3 memperlihatkan gambar penampang benda uji. Pen-binder dipasang pada 2 sisi berselingan pada arah vertikal sehingga terjadi pemerataan perkuatan pada keempat sisi kolom. 


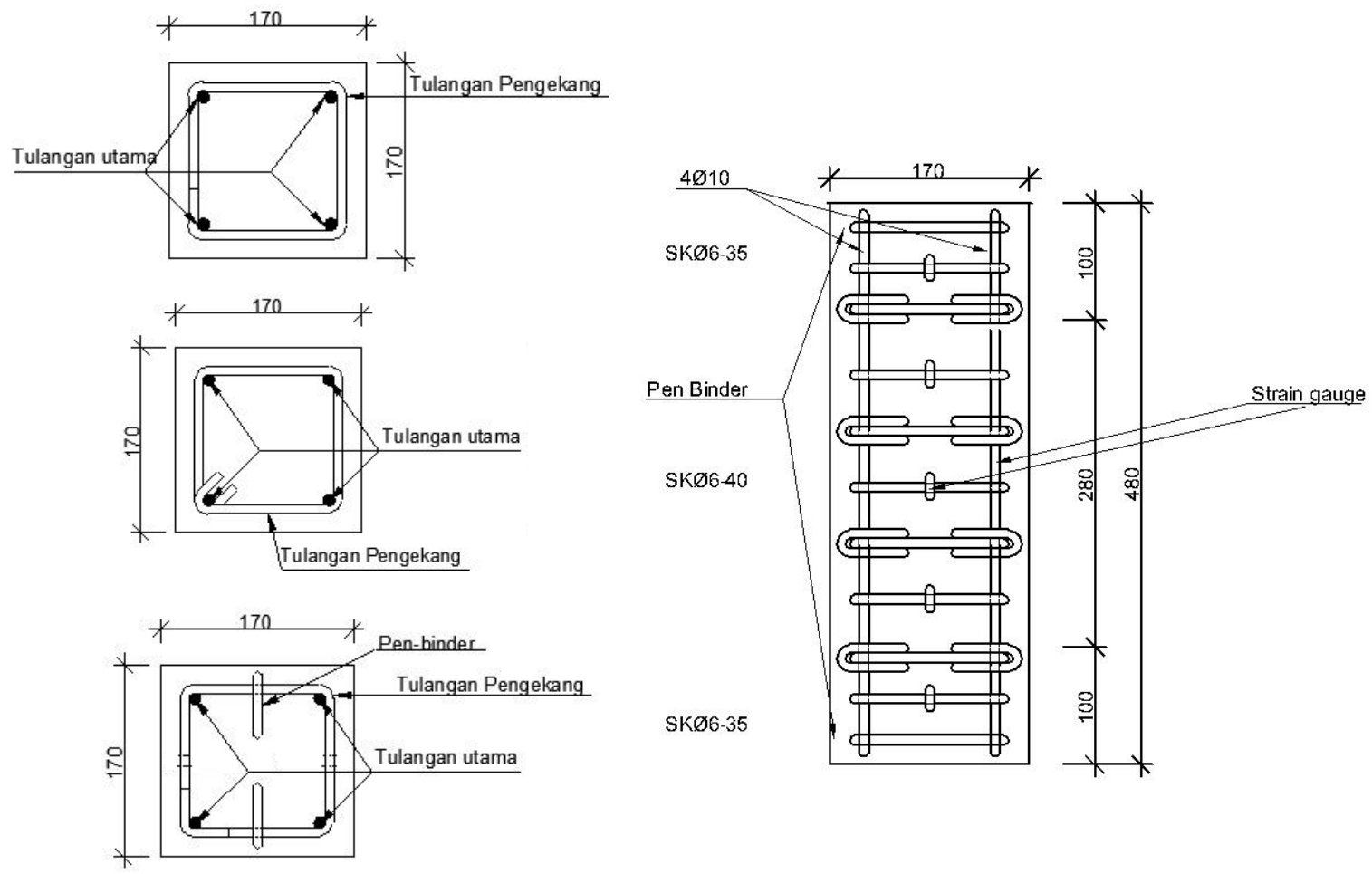

Gambar 3. Detail benda uji kolom

Pemasangan pen-binder dilakukan setelah umur beton mencapai 28 hari. Pemasangan dilakukan dengan melakukan pengeboran beton untuk membuat lobang sehingga pen-binder dapat masuk dan mengkait tulangan pengekang. Setelah pen-binder terpasang maka lobang ditutup dengan menggunakan grouting. Pemasangan pen-binder dipasang pada ke dua sisi yang berlawanan dari tulangan pengekang,
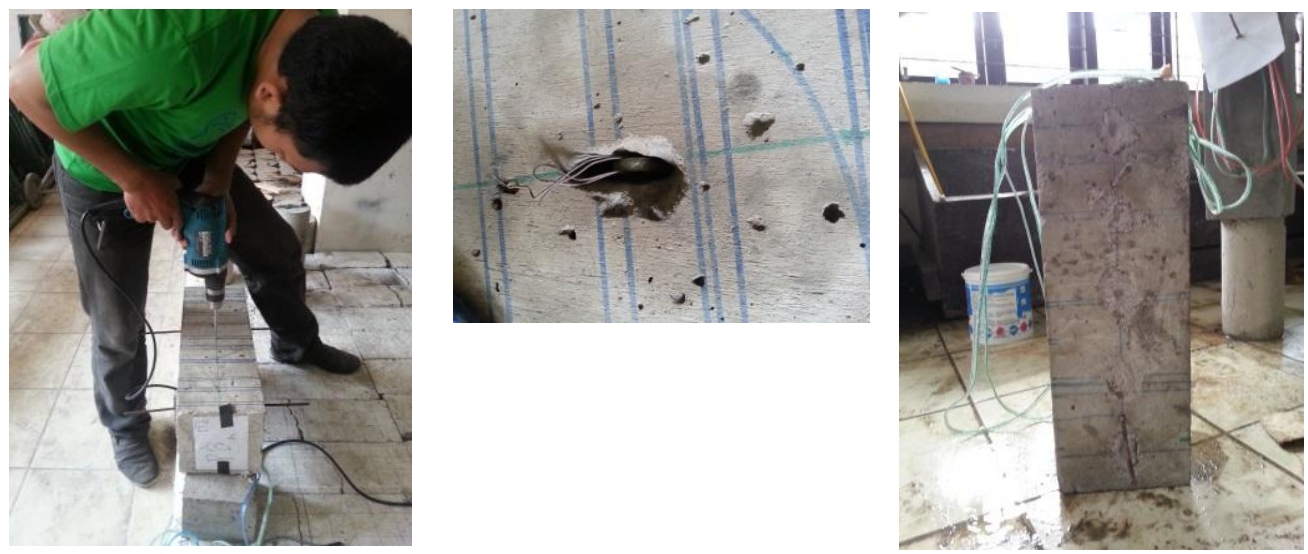

Gambar 4.Proses pemasangan pen-binder 


\subsection{Set Up Alat Pengujian}

Untuk keperluan pengujian ini daerah yang akan dianalisis berada ditengah benda uji kolom sepanjang $280 \mathrm{~mm}$ sehingga pada daerah tersebut dipasang LVDT arah vertikal pada salah satu sisi. LVDT digunakan untuk mengukur deformasi aksial kolom serta memeriksa konsentrisitas pembebanan yang terjadi pada kolom. Gambar mengenai pemasangan LVDT dapat dilihat pada Gambar 5.

Untuk menganalisis besarnya regangan pada tulangan maka strain gauge dipasang pada tulangan utama dan tulangan pengekang yang posisinya berada di tengah tinggi kolom. Strain gauge berfungsi untuk mengetahui regangan yang terjadi pada baja tulangan kolom, sehingga kondisi tulangan ketika mengalami leleh dapat diketahui.

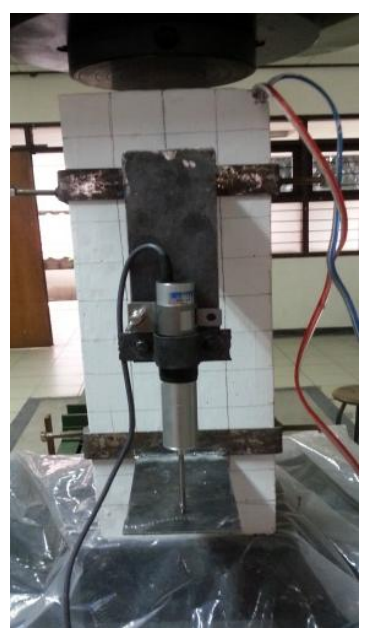

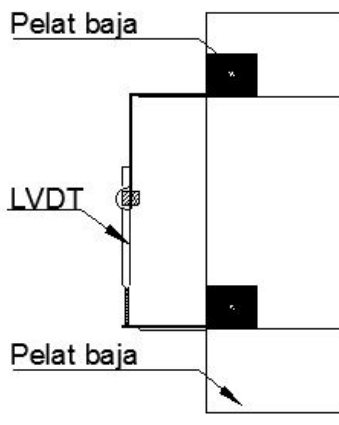

Tampak samping

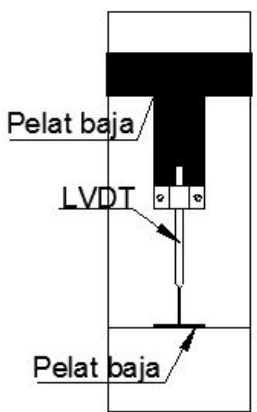

Tampak depan

Gambar 5. Pemasangan dan posisi LVDT pada benda uji

Pengujian tekan kolom dilakukan dengan menggunakan mesin uji tekan UTM berkapasitas $1000 \mathrm{kN}$ seperti pada Gambar 6. Kecepatan pembebanan yang dilakukan adalah $0,01 \mathrm{MPa} / \mathrm{mm}$. Pembebanan dilakukan hingga terlihat penurunan beban secara signifikan atau hingga benda uji mengalami kegagalan. Proses pembebanan dicatat mulai dari retak, terlepasnya selimut beton hingga kolom mengalami keruntuhan.

Seluruh data-data pengujian yang didapat dari pemasangan strain gauge, LVDT dan gaya tekan alat yang dapat langsung dimonitor melalui komputer dan dicatat oleh data logger (Gambar 6). Pengamatan visual juga dilakukan untuk melihat perilaku retak kolom benda uji pada saat mengalami kenaikan beban aksial. Hasil pengamatan didokumentasikan untuk keperluan analisis visual. 

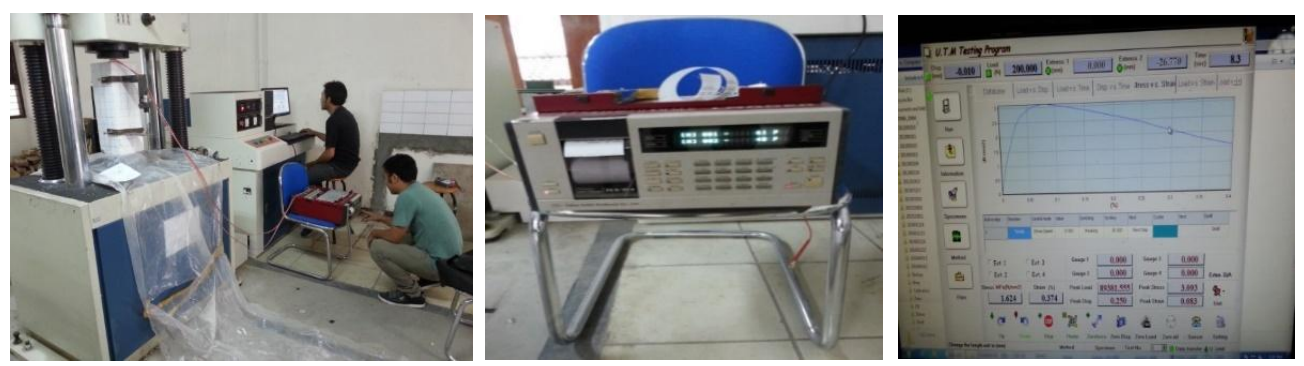

Gambar 6.Alat uji tekan, data logger dan grafik pada monitor

\section{ANALISIS HASIL PENGUJIAN}

\subsection{Analisis Visual}

Untuk mengetahui prilaku tulangan utama dan tulangan pengekang yang berada didalam beton, sebagian selimut beton yang belum hancur dikelupas sehingga terlihat tulangan utama dan tulangan pengekangnya. Gambar benda uji yang telah terkelupas selimut betonnya dapat dilihat pada Gambar 7 hingga Gambar 9.
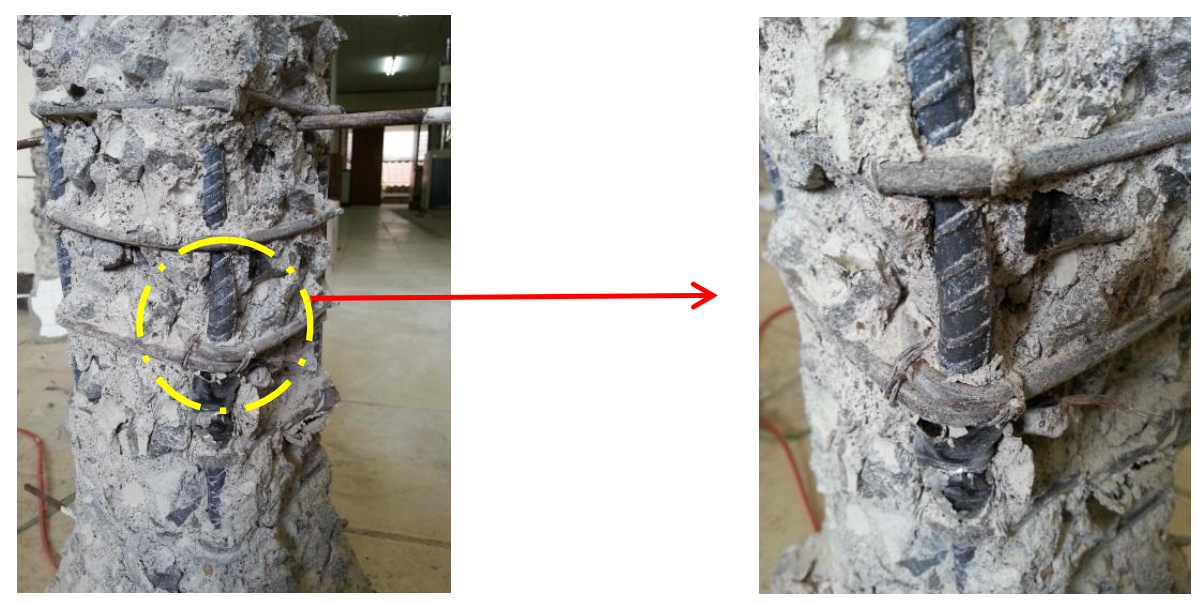

Gambar 7. Hasil pengujian kolom K135

Gambar 7 memperlihatkan kondisi kolom dengan kait standar (K135) yang mengalami kegagalan tekuk akibat lelehnya tulangan utama akibat beban aksial.Pengamatan visual memperlihatkan tulangan pengekang berfungsi dengan baik untuk menahan tulangan utama dan inti beton.

Hasil pengujian kolom K90 dapat dilihat pada Gambar 8, terlihat bahwa kait terbuka dan tulangan longitudinal mengalami tekuk berlebih pada daerah sudut yang 
terdapat kait $90^{\circ}$. Hal ini memperlihatkan bahwa tulangan pengekang tidak berfungsi dengan baik untuk mengekang inti kolom, terlihat pada daerah tersebut sebagian inti kolom sudah terlepas.
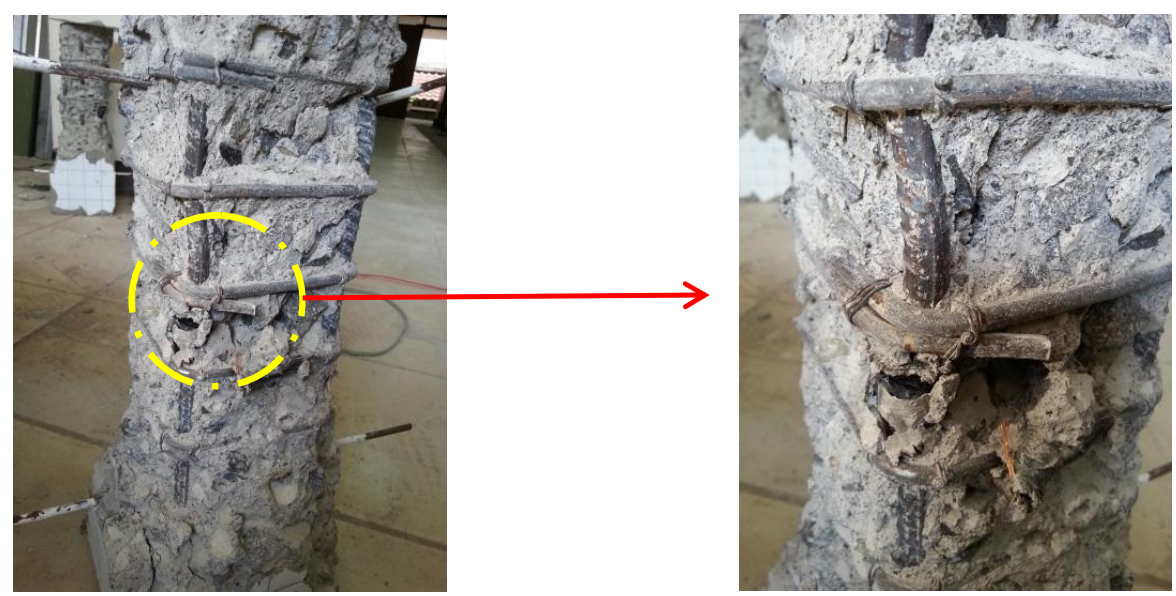

Gambar 8. Hasil pengujian kolom K90

Hasil pengujian secara visual pada kolom KPB dapat dilihat pada Gambar 9 berikut. Pengamatan visual memperlihatkan perkuatan dengan pen-binder memberikan hasil yang memuaskan. Tulangan pengekang sekalipun dipasang dengan cara tidak standar menghasilkan kekangan yang baik.

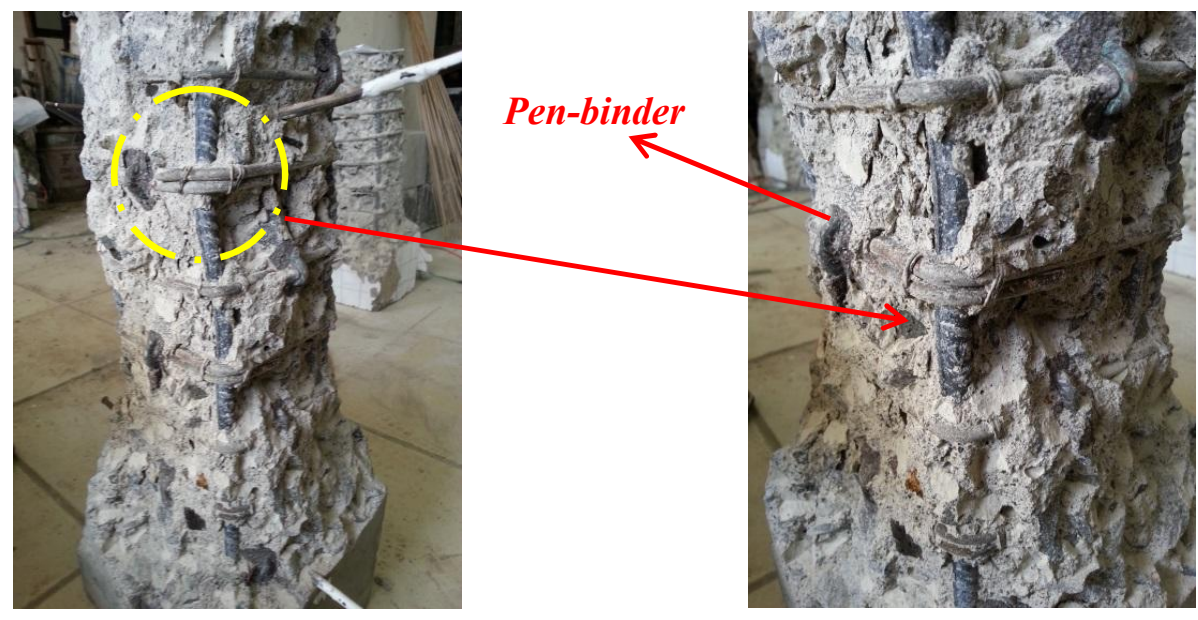

Gambar 9. Hasil pengujian kolom KPB 
Pengamatan secara visual memperlihatkan bahwa penggunaan pen-binder sebagai perkuatan kolom beton eksisting yang telah dibangun dengan kait tidak standar atau kait $90^{\circ}$ memberikan hasil yang pengekangan yang baik.

\subsection{Pola Retak Kolom}

Pada umumnya benda uji menunjukan pola keruntuhan yang hampir sama hingga mencapai beban maksimum, yang membedakan adalah kecepatan keruntuhannya. Dari pengamatan visual keruntuhan kolom diawali retak-retak rambut diagonal, kemudian retak-retak melebar, setelah itu selimut beton mulai terkelupas lalu pada saat beban maksimum kolom mengalami keruntuhan pada bagian tengah terlebih dahulu. Pola retak kolom setiap tipe kolom dapat dilihat pada Gambar 10 hingga Gambar 12.Pola retak keruntuhan kolom K135 dapat dilihat pada Gambar 10 berikut.

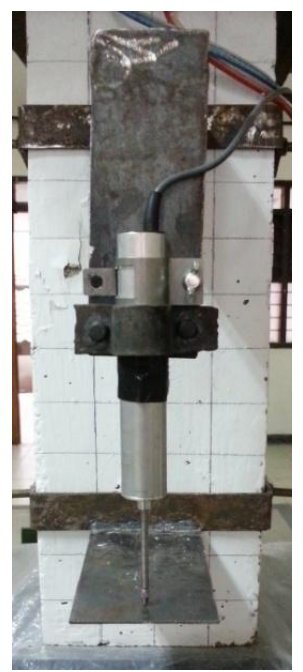

(a)

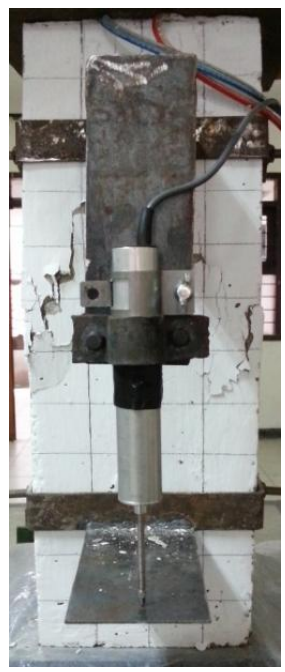

(b)

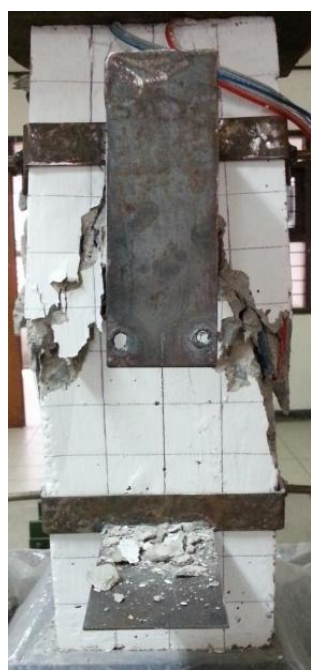

(c)

Gambar 10. Proses pengujian kuat tekan kolom mulai dari; (a) retak; (b) terkelupasnya selimut beton; (c) keruntuhan kolom K135

Terkelupasnya selimut beton membuat tulangan pengekang mulai berfungsi memberi kekangan kepada inti kolom agar tetap berada pada posisinya sehingga benda uji kolom sanggup menerima beban maksimum dalam waktu yang relatif lama sebelum mencapai keruntuhannya. Pada benda uji kolom yang memiliki kait tidak standar (K90) keruntuhan terjadi dengan mendadak sebagai akibat dari menekuknya tulangan pengekang. Pada Gambar 11 memperlihatkan urutan pola retak yang terjadi pada tulangan pengekang dengan kait tidak standar. 


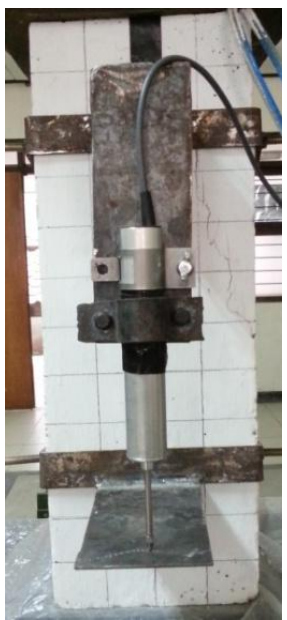

(a)

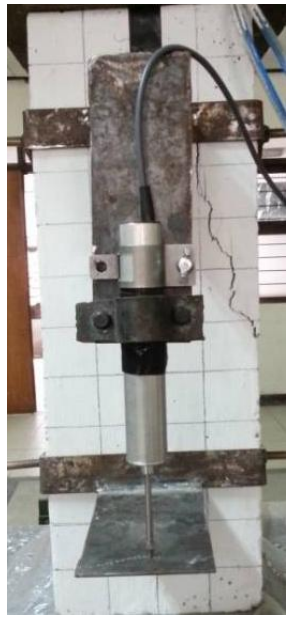

(b)

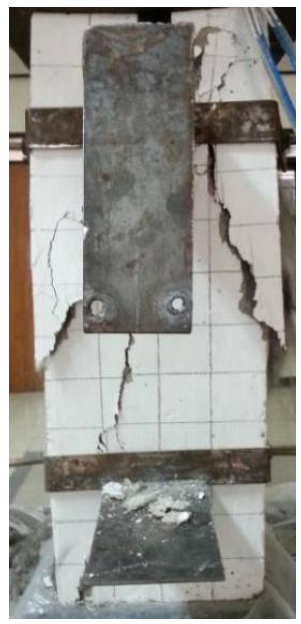

(c)

Gambar 11. Proses pengujian kuat tekan kolom mulai dari; (a) retak; (b) terkelupasnya selimut beton; (c) keruntuhan kolom K90

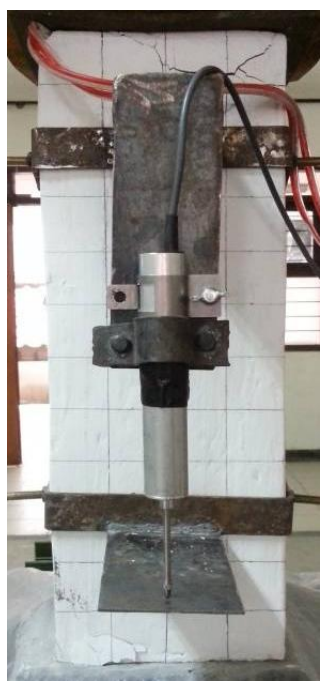

(a)

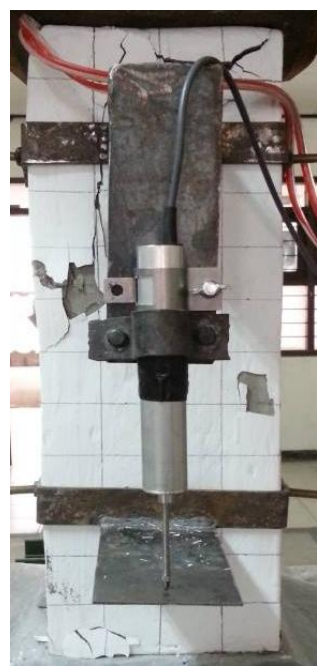

(b)

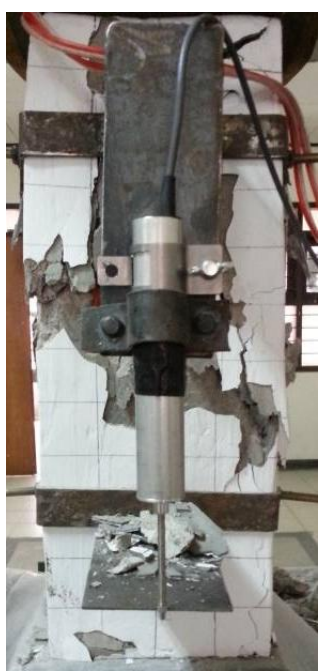

(c)

Gambar 12. Proses pengujian kuat tekan kolom mulai dari (a) retak (b) terkelupasnya selimut beton (c) keruntuhan kolom dengan KPB

\subsection{Beban dan Regangan Aksial Benda Uji}

Kapasitas beban aksial maksimum yang dapat ditahan oleh benda uji dapat dilihat dari hasil pembacaan nilai maksimum yang terdapat pada UTM, sementara itu nilai regangan yang terjadi dapat diukur melalui LVDT yang dipasang pada benda uji. Hasil 
uji yang digunakan adalah hasil uji rata-rata dari tiga benda uji, hasil benda uji kolom setiap tipe dapat dilihat pada Tabel 1dan Gambar 13 berikut.

Tabel 1. Tabel hasil pengujian berdasarkan alat LVDT

\begin{tabular}{|l|c|c|c|c|c|c|}
\hline & \multicolumn{2}{|c|}{ Kolom K135 } & \multicolumn{2}{c|}{ Kolom K90 } & \multicolumn{2}{c|}{ Kolom KPB } \\
\cline { 2 - 7 } & $\begin{array}{c}\text { Beban } \\
\text { aksial } \\
(\mathrm{kN})\end{array}$ & Regangan & $\begin{array}{c}\text { Beban } \\
\text { aksial } \\
(\mathrm{kN})\end{array}$ & Regangan & $\begin{array}{c}\text { Beban } \\
\text { aksial } \\
(\mathrm{kN})\end{array}$ & Regangan \\
\hline Beban leleh & 340,00 & 0,0020 & 395,00 & 0,0020 & 335,00 & 0,0020 \\
\hline $\begin{array}{l}\text { Beban } \\
\text { maksimum }\end{array}$ & 447,26 & 0,011 & 471,77 & 0,0026 & 441,31 & 0,01 \\
\hline $\begin{array}{l}\text { Beban } \\
\text { ultimate }\end{array}$ & 380,17 & 0.0150 & 401,0 & 0,0026 & 375,11 & 0,035 \\
\hline Daktilitas & & 7.5 & & 1.3 & & 17.5 \\
\hline
\end{tabular}

Tabel 1 memperlihatkan besarnya beban yang terjadi pada saat tulangan longitudinal mencapai leleh (beban leleh) dan pada saat beban ultimate terjadi. Beban leleh berkorelasi dengan nilai beban pada saat tulangan longitudinal mencapai nilai leleh. Beban ultimate diambil pada titik saat terjadi penurunan kapasitas kolom sebesar 15\% dari beban maksimum (puncak) yang terjadi. Regangan yang dianalisis adalah regangan aksial kolom benda uji yang didapat dari deformasi aksial hasil pengukuran LVDT dibagi panjang daerah pengujian $(280 \mathrm{~mm})$. Besarnya daktilitas dihitung dari perbandingan regangan ultimate dengan regangan lelehnya. Kolom dengan kait tidak standar memiliki beban aksial maksimum yang relatif sedikit lebih tinggi dari benda uji lainnya, meskipun begitu apabila dilihat dari beban lelehnya terlihat bahwa kolom dengan pen-binder lebih dulu mengalami leleh tulangan longitudinal. Hal ini menunjukkan bahwa kekangan berfungsi dengan baik sehingga tulangan kolom mengalami kegagalan leleh terlebih dahulu. Sementara pada benda uji kolom dengan tulangan kait tidak standar terjadi pergeseran kait sehingga segera setelah beban maksimum tercapai segera terjadi kegagalan (mencapai beban ultimate) pada regangan yang sama. Benda uji kolom standar memiliki perilaku yang lebih baik daripada kait tidak standar, kolom dapat mempertahankan kapasitas maksimumnya setelah leleh hingga mengalami kegagalan.

Gambar 13 memperlihatkan grafik beban dan regangan yang terjadi untuk masing-masing benda uji. Berdasarkan grafik terlihat bahwa tulangan dengan kait tidak standar $90^{\circ}$ mengalami kegagalan yang mendadak, hal ini dapat dilihat dari kurva yang mendadak mengalami penurunan gaya aksial pada regangan yang masih awal yaitu 0,0026, sehingga dapat dikatakan benda uji memiliki daktilitas 1,3. 


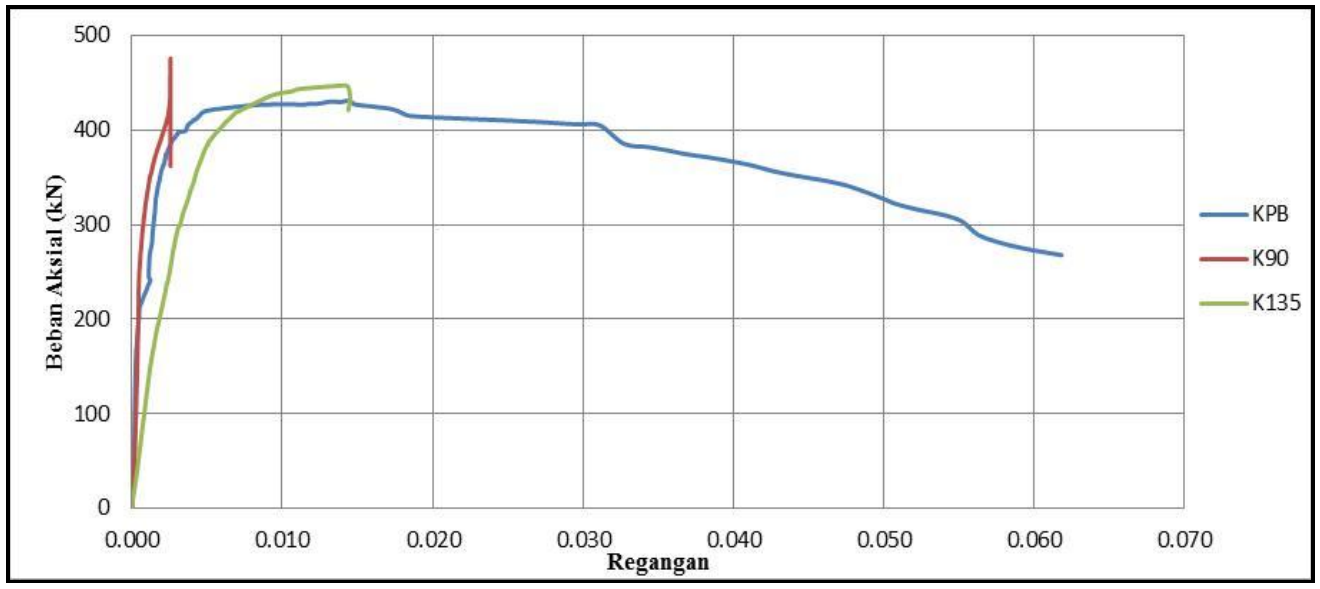

Gambar 13 GrafikBeban dan Regangan benda uji

Benda uji dengan kait standar $135^{\circ}$ memperlihatkan perilaku daktilitas yang lebih baik, setelah mengalami leleh pada tulangan longitudinal kapasitas aksial kolom tidak segera menurun sehingga menghasilkan nilai daktilitas yang lebih baik yaitu sebesar 7,5. Benda uji dengan pen-binder memberikan perilaku pengekangan yang jauh lebih baik. Pada grafik terlihat perilaku benda uji dengan perkuatan penbinder menghasilkan daktilitas yang lebih baik yaitu sebesar 17,5, terjadi peningkatan sebesar 133\%. Kondisi ini memperlihatkan bahwa penggunaan pen-binder dapat memberikan hasil yang lebih baik dalam hal daktilitasnya daripada penggunaan kait standar, perilaku kolom dengan daktilitas yang tinggi sangat diperlukan untuk struktur yang dibangun di daerah rawan gempa.

\section{KESIMPULAN}

Dari hasil penelitian didapatkan kesimpulan sebagai berikut :

1. Mekanisme keruntuhan pada kolom hingga mencapai beban maksimum umumnya sama. Pola keruntuhan kolom diawali retak-retak rambut diagonal, kemudian retakretak melabar, setelah itu selimut beton mulai terkelupas dilanjutkan tulangan longitudinal mencapai kapasitas lelehnya, setelah beban maksimum tercapai terjadi penurunan kapasitas aksialnya secara signifikan.

2. Benda uji kolom dengan tulangan tidak standar (kait $90^{\circ}$ ) mengalami penurunan kapasitas aksial yang mendadak, hal ini terjadi karena kait segera terbuka setelah tegangan leleh tulangan longitudinal tercapai. 
3. Penggunaan pen-binder memberikan kemampuan daktilitas yang jauh lebih baik daripada tulangan sengkang yang tidak standar maupun tulangan pengekang yang standar (kait $\left.135^{\circ}\right)$.

4. Daktilitas yang terjadi pada kolom tidak standar, kolom standar dan kolom dengan perkuatan pen-binder berturut-turut adalah 1,3 , 7,5 dan 17,5. Terjadi peningkatan sebesar $133 \%$ daktilitas apabila menggunakan perkuatan dengan pen-binder dari pada penggunaan kolom standar.

\section{SARAN}

Perlunya dilakukan penelitian lebih lanjut mengenai perkuatan kolom eksisting dengan dimensi lingkaran mengggunakan perkuatan pen-binder agar lebih efisien dalam pemasangan dan penggunannya.

\section{DAFTAR PUSTAKA}

1. Bae, S. and Bayrak, O.(2008)," Seismic Performance of Full Scale Reinforced Concrete Column", ACI Structural Journal, V. 105, No. 2, March-Apr., pp. 123133.

2. James G.M, James K.Wight (2005)." Reinforced Concrete Mechanics and Design, Fourth Edition", Prentice Hall.

3. Kristianto, A. et al. (2012)," Confinement of Reinforced Concrete Columns with Non Compliance Confining Reinforcement plus Supplemental Pen-Binder", ITB J. Eng. Sci., Vol. 44, No. 3, pp. 220-237

4. Paultre P.; Legeron F.,(2008). " Confinement Reinforcement Design for Reinforced Concrete Columns", ASCE Journal of Structural Engineering, Vol 134. No5 May 2008.pp738-749

5. Purwono, R., Tavio, Imran, I., Raka, I.G.P, 2006, Indonesian Concrete Code for Buildings ( SNI 03-2847-2002 ) with Commentary , ITS Press, Surabaya, Indonesia.

6. Sheikh, S.A and Uzumeri, S.M.(1980)."Strength and Ductility of Tied Concrete Column", Proceedings, ASCE, V.106, ST5, May 1980, pp 1079-1102.

7. Sheikh, S. A., and Yeh, C.,(1990). "Tied Concrete Columns under Axial Load and Flexure," Journal of Structural Engineering, ASCE, V. 116, No. 10, Oct. 1990, pp. 2780-2800.

8. Razvi S.R and Saatcioglu M.(1994) "Strength and Deformability of confined High-Strength Concrete Columns ",ACI Structural Journal, V. 91, No. 6, NovDec. 1994, pp. 1-10.

9. Watanabe, F.; Muguruma, H.; Matsutani, T.; and Sanda, D.(1987).”Utilization of High Strength Concrete for Reinforced Concrete High Rise Buildings in Seismic Area," Utilization of High Strength Concrete Proceeding, Stavanger, Norway, Tapir Publishers, pp 655-666. 